\title{
Glucose homeostasis and insulin resistance: prevalence, gender differences and predictors in adolescents
}

Irena Aldhoon-Hainerová ${ }^{1,2^{*}+}$, Hana Zamrazilová ${ }^{\dagger}$, Lenka Dušátková1,3, Barbora Sedláčková ${ }^{1,3}$, Petr Hlavatý1, Martin Hill', Richard Hampl ${ }^{1}$, Marie Kunešová ${ }^{1}$ and Vojtěch Hainer ${ }^{1}$

\begin{abstract}
Background: Adolescence, due to transient pubertal insulin resistance (IR), is associated with a higher risk for disturbances of glucose metabolism. The aim of our study was 1) to investigate the prevalence of disturbances of glucose metabolism, 2) to define gender specific homeostasis model assessment of insulin resistance (HOMA-IR) thresholds associated with increased cardiometabolic risks and 3) to provide predictors of HOMA-IR.

Methods: The studied cohort consisted of Czech adolescents aged 13.0-17.9 years: 1,518 individuals of general population and three studied groups according weight category (615 normal weight, 230 overweight and 683 obese). The prevalence of IR, impaired fasting glucose (IFG) and type 2 diabetes was assessed. Risky HOMA-IR thresholds based on components of metabolic syndrome were investigated. HOMA-IR prediction was calculated taking into account age, blood pressure, multiple anthropometric, biochemical and hormonal parameters.

Results: In general population cohort, the prevalence of IFG and type 2 diabetes was $7.0 \%$ and $<0.5 \%$, respectively. Boys regardless of weight presented significantly higher levels of blood glucose and higher prevalence of IFG than girls. Obese boys were found more insulin resistant than obese girls. HOMA-IR thresholds of 3.6 for girls and 4.4 for boys were associated with increased cardiometabolic risks. For both genders, the model of HOMA-IR prediction was composed of age, BMI, ratio of free triiodthyronine to free thyroxine, gamma-glutamyltransferase activity and levels of triglycerides and sex hormone-binding globulin.

Conclusions: The type 2 diabetes in adolescents, including those who were obese, was rarely diagnosed. Obese adolescent boys were at greater risk for IR and for IFG than obese girls. In adolescence, thresholds of HOMA-IR in contrast to predictors were found gender specific.
\end{abstract}

Keywords: Adolescence, Glucose homeostasis, HOMA-IR prediction, Insulin resistance, Metabolic syndrome, Obesity, Type 2 diabetes

\section{Introduction}

Insulin resistance (IR) together with an impaired insulin secretion does play a role in the pathogenesis of type 2 diabetes [1]. A degree of IR is influenced by age, gender, race and ethnicity, a stage of sexual development, total adiposity and fat distribution [2-4]. To date, there is

\footnotetext{
* Correspondence: ihainer@hotmail.com

${ }^{\dagger}$ Equal contributors

'Institute of Endocrinology, Obesity Management Center, Národní 8, 11694 Prague 1, Czech Republic

${ }^{2}$ Department of Pediatrics and Center for Research of Diabetes, Metabolism and Nutrition, Third Faculty of Medicine, Charles University, Šrobárova 50, 10034 Prague 10, Czech Republic

Full list of author information is available at the end of the article
}

no universally accepted pediatric definition for IR. The homeostasis model assessment of insulin resistance (HOMA-IR) is simple method to measure IR [5] and even in obese children strongly correlates with the results derived from clamp studies [6]. An identification of insulin resistant adolescent is highly important as the occurrence of type 2 diabetes coincides with the peak of pubertal IR [7]. The interpretation of HOMA-IR value is particularly challenging at adolescence. Several HOMA-IR thresholds to define IR in adolescence have been suggested [8-11]. 
Fasting insulin level is sometimes used as a marker of IR. A study of Moran et al. demonstrated a significant correlation between glucose uptake during insulin clamp and fasting insulin levels [4]. IR, particularly in girls, has been shown to be associated with a decreased ratio of C-peptide to insulin [12].

Patients with impaired fasting glucose (IFG) are referred to as having prediabetes and they are considered at risk for future development of type 2 diabetes [13]. Data from National Health and Nutrition Examination Survey showed that the prevalence of IFG in United States (US) adolescents was 7.0\% [14]. Higher prevalence of IFG is usually found in obese adolescents than in normal weight counterparts [14]. The prevalence of type 2 diabetes in children varies across the world but an increasing trend due to obesity epidemic is observed. A higher prevalence of type 2 diabetes is found in the US children mainly in those of non-White European descent [15]. In the Northern and Central Europe type 2 diabetes is still, even in obese children, rarely diagnosed and its prevalence ranges 0.5 to $1.5 \%$ [16-18].

Metabolic syndrome due to IR predisposes affected individuals to type 2 diabetes. Tresaco et al. showed that HOMA-IR is a useful tool to detect children and adolescents with this condition [8]. Several studies investigated predictors of pubertal IR e.g. anthropometric parameters [19], body composition [20], adipokines [20-22] and several hormones [23,24].

The first aim of our study was to reveal the prevalence of IR, IFG and type 2 diabetes in normal weight, overweight and obese Czech adolescents, and in a general population cohort. Second, we aimed to investigate the effects of gender and weight status on levels of blood glucose, insulin, $\mathrm{C}$-peptide, $\mathrm{C}$-peptide to insulin ratio and HOMA-IR. Our third aim was to examine the level of HOMA-IR in relation to the presence of parameters defining metabolic syndrome. Finally, we intended to assess major predictors of HOMA-IR from the whole cohort of studied Czech adolescents.

\section{Methods}

\section{Study population}

The cohort for the present study was constituted of Czech adolescents aged 13.0-17.9 years from the Childhood Obesity Prevalence And Treatment project which consists of a general population cohort (all body weight categories) and of in- and out-patient weight intervention cohort (overweight and obese individuals only). Analyses were performed in 1,518 Czech adolescents of general population (775 girls, 743 boys; $23.9 \%$ of girls and $29.3 \%$ of boys were either overweight or obese) and in three weight categories: 615 normal weight (322 girls and 293 boys) for Body Mass Index (BMI) 25.-75. percentile (derived from the general population cohort only), 230 overweight (116 girls, 114 boys) for BMI 90.-97. percentile and 683 obese (381 girls, 302 boys) for BMI $\geq 97$. percentile for sex and age of the Czech reference [25]. The overweight and obese groups were constituted from both the general population cohort and from the intervention study of the above mentioned project. A detailed design of the project has already been described [26].

\section{Ethics statement}

The study protocol was approved by the Ethical Committee of the Institute of Endocrinology in Prague and was in accordance with the Helsinki declaration II. All participants and their parent(s)/guardian(s) signed an informed consent before the initiation of study procedures.

\section{Clinical examination, anthropometry and body composition}

Following parameters were investigated: age; systolic and diastolic blood pressure; anthropometric parameters and indexes \{weight, height, waist circumference, abdominal circumference, hip circumference, arm circumference and theirs $\mathrm{z}$ scores; sagittal abdominal diameter; skinfolds: suprailiac, biceps, triceps, abdomen and subscapular; fat assessed by bioimpedance (Tanita BC-418 MA, Tanita AB 140 MA Viscan, Tanita Corporation, Tokyo, Japan): trunk fat, total body fat, and visceral fat; indexes: BMI, BMI z-score, waist-to-hip ratio, waist-to-height ratio, body adiposity index: [(hip circumference)/(height) 1.5] - 18, a body shape index: waist circumference divided by BMI2/3 height1/2\}.

\section{Biochemical and hormonal parameters}

We investigated following biochemical parameters: blood glucose, total cholesterol, high-density lipoprotein cholesterol, low-density lipoprotein cholesterol, triglyceride (TG), C-peptide, C-reactive protein, uric acid, activity of alanine aminotransferase, aspartate aminotransferase and gamma-glutamyl aminotransferase (GMT) and the following hormonal parameters: insulin, free triiodothyronine (fT3), free thyroxine (fT4), thyroid stimulating hormone, prolactin, cortisol, dehydroepiandrosterone sulfate, sex hormone-binding globulin (SHBG), testosterone, luteinizing hormone, follicle stimulating hormone, estradiol, progesterone, adiponectin, adipsin, ghrelin, glucose insulinotropic peptide, glucagon-like-peptide 1, glucagon, leptin, plasminogen activator inhibitor-1 (PAI-1), resistin and visfatin. Ratio of fT3 to fT4 was calculated.

Anthropometric procedures, laboratory assays and evaluations have been described in a previously published paper [26]. 


\section{Definitions of glucose homeostasis disturbances, IR and metabolic syndrome}

According to the American Diabetes Association IFG is defined by fasting blood glucose 5.6-6.9 $\mathrm{mmol} / \mathrm{l}$ and type 2 diabetes by fasting blood glucose $\geq 7.0 \mathrm{mmol} / \mathrm{l}$ [13]. IR was evaluated by the HOMA-IR that was calculated by the following formula: fasting plasma insulin (microunits per liter) $\times$ fasting glucose (millimoles per liter) $/ 22.5$ [5]. In order to estimate IR in our cohorts, we used the thresholds of HOMA-IR > 2.5 and > 4.0 [5,27]. HOMA-IR $\leq 4.0$ was shown to be associated with a little probability of type 2 diabetes development [28]. Parameters of the International Diabetes Federation (IDF) definition of the metabolic syndrome were used in our analyses [29].

\section{Statistical analyses}

To eliminate skewed data distribution and heteroscedasticity, the original data were transformed to a Gaussian distribution by a Box-Cox transformation before further processing using the statistical software Statgraphics Centurion, version XV from Statpoint Inc. (Herndon, Virginia, USA). Data were analyzed using non-parametric tests: Mann-Whitney test (for differences between two independent groups) and Kruskal-Wallis multiple comparisons (for differences among three or more independent groups). Categorical data were tested by Chi-square test. The statistical software NCSS 2004 (Kaysville, Utah, 190 USA) were used. P-value (two-tailed) $<0.05$ was considered statistically significant.

In order to detect relationships between HOMA-IR and studied parameters we applied a multivariate regression with reduction of dimensionality, known as OPLS [30]. All subjects that had been assessed for the present study were used for the prediction of HOMA-IR. Analyses were performed separately for boys and girls. OPLS allowed us to find a model predicting HOMA-IR based both on the minimum number of widely available parameters but also on the best predictability. We tested the relevance of individual variables for the model using a criterion variable importance. At the first stage, all above mentioned parameters, excluding levels of blood glucose and insulin, were studied for HOMA-IR prediction. We constructed two models for HOMA-IR prediction. The first model comprised components with the highest predictability. The second model was based on the first model and aimed at components that are widely available in clinical practice (clinical model).

The statistical software SIMCA-P + Version 12.0.0.0 from Umetrics $A B$ (Umeå, Sweden) was used for data analyses. The software enabled us to find the number of the relevant components utilizing the prediction error sum of squares and also allowed the detection of multivariate non-homogeneities and testing the multivariate normal distribution and homoscedasticity.

\section{Results}

Disturbances of glucose metabolism and IR

Basic characteristics and only those parameters, which were found as major predictors of HOMA-IR, for all studied groups are presented in Table 1. Between girls and boys of each studied group, there were no differences in age and BMI z-score except for BMI z-score in the overweight cohort (Table 1). Table 1 also shows the prevalence of IFG, type 2 diabetes and of IR defined by two thresholds of HOMA-IR in each cohort. IFG was more common in boys than in girls regardless of weight status (Table 1).

Significant differences in BMI z-scores, levels of insulin, $\mathrm{C}$-peptide, $\mathrm{C}$-peptide to insulin ratio (except for the ratio in overweight vs. obese girls) and HOMA-IR ( $\mathrm{p}=0.000)$ but not in blood glucose level were found when weight categories were compared between each other (normal weight vs. overweight; normal weight vs. obese; overweight vs. obese) in analyses within each gender (data not shown). In all cohorts, boys presented significantly greater level of blood glucose than girls $(\mathrm{p}=0.000)$ (Table 1$)$. Levels of insulin and C-peptide were significantly higher in girls than in boys in the normal weight and in the general population cohorts $(\mathrm{p}=0.001)$ (Table 1$)$. However, obese boys had significantly higher insulin, C-peptide and HOMA-IR than obese girls (Table 1). C-peptide to insulin ratio gradually decreased with an increasing body weight. No gender differences in this ratio were noted except for obese individuals (Table 1).

\section{HOMA-IR thresholds associated with cardiometabolic risks} In both genders, HOMA-IR gradually increased with increasing number of parameters derived from metabolic syndrome definition. HOMA-IR of 3.6 for girls and of 4.4 for boys were identified as cut-off values that corresponded to increased cardiometabolic risks defined as a presence of three components of metabolic syndrome (Table 2). These HOMA-IR values represent the 84.0 and 87.0 percentile in girls and boys of general population, respectively.

\section{HOMA-IR prediction}

Out of 68 analyzed parameters, 57 parameters in boys (43.2\% variability of the dependent variable explained by OPLS method) and 51 parameters in girls (30.1\% variability of the dependent variable explained by OPLS method) showed a significance to HOMA-IR prediction. At this stage, we first selected those parameters that presented with the highest prediction and were more or less shared by both genders. Similar prediction of most of the studied anthropometric parameters were found, thus, for the further model analyses we only included BMI. In the predictive model, age, BMI, ratio of $\mathrm{fT} 3$ to $\mathrm{fT} 4$, GMT activity, levels of TG, SHBG, leptin, PAI-1, ghrelin, adiponectin and testosterone explained $41.4 \%$ of the HOMA-IR in boys. Except for the level of testosterone, girls presented with the 
Table 1 Baseline characteristics of studied cohorts - general population, normal weight, overweight and obese

\begin{tabular}{|c|c|c|c|c|c|c|c|c|c|c|c|c|}
\hline \multirow[t]{2}{*}{ Parameter } & \multicolumn{3}{|c|}{ General population } & \multicolumn{3}{|c|}{ Normal weight } & \multicolumn{3}{|c|}{ Overweight } & \multicolumn{3}{|c|}{ Obese } \\
\hline & Girls $(n=775)$ & Boys $(n=743)$ & $\mathbf{p}$ & Girls $(n=322)$ & Boys $(n=293)$ & $\mathbf{p}$ & Girls $(n=116)$ & Boys $(n=114)$ & $\mathbf{p}$ & Girls $(n=381)$ & Boys $(n=302)$ & $\mathbf{p}$ \\
\hline Age $^{*}$ (years) & $\begin{array}{c}16.02 \\
(15.10 ; 17.00)\end{array}$ & $16.08(15.13 ; 17.00)$ & 0.745 & $\begin{array}{c}16.12 \\
(15.16 ; 17.02)\end{array}$ & $\begin{array}{c}15.87 \\
(15.08 ; 16.84)\end{array}$ & 0.097 & $\begin{array}{c}15.66 \\
(14.82 ; 16.92)\end{array}$ & $\begin{array}{c}16.04 \\
(14.46 ; 17.08)\end{array}$ & 0.465 & $15.18(14.07 ; 16.42)$ & $\begin{array}{c}15.21 \\
(14.03 ; 16.56)\end{array}$ & 0.990 \\
\hline BMI $^{*}\left(\mathrm{~kg} / \mathrm{m}^{2}\right)$ & $\begin{array}{c}21.25 \\
(19.41 ; 23.61)\end{array}$ & $\begin{array}{c}21.47 \\
(19.64 ; 24.48)\end{array}$ & 0.022 & $\begin{array}{c}20.28 \\
(19.58 ; 21.15)\end{array}$ & $\begin{array}{c}20.29 \\
(19.58 ; 21.08)\end{array}$ & 0.963 & $\begin{array}{c}24.79 \\
(24.17 ; 25.48)\end{array}$ & $\begin{array}{c}24.75 \\
(24.08 ; 25.70)\end{array}$ & 0.934 & $29.95(27.89 ; 33.07)$ & $\begin{array}{c}30.34 \\
(28.13 ; 33.95)\end{array}$ & 0.146 \\
\hline BMI $^{*}$ z-score & $\begin{array}{c}0.24 \\
(-0.46 ; 1.15)\end{array}$ & $\begin{array}{c}0.22 \\
(-0.39 ; 1.25)\end{array}$ & 0.280 & $-0.12(-0.41 ; 0.19)$ & $-0.15(-0.39 ; 0.10)$ & 0.114 & $1.60(1.39 ; 1.60)$ & $1.43(1.22 ; 1.66)$ & 0.000 & $3.53(2.78 ; 4.65)$ & $3.50(2.69 ; 4.72)$ & 0.506 \\
\hline $\mathrm{FBG}^{*}(\mathrm{mmol} / \mathrm{l})$ & $4.83(4.55 ; 5.09)$ & $5.09(4.84 ; 5.35)$ & 0.000 & $4.79(4.52 ; 5.06)$ & $5.08(4.82 ; 5.31)$ & 0.000 & $4.79(4.52 ; 5.07)$ & $5.13(4.90 ; 5.43)$ & 0.000 & $4.82(4.52 ; 5.14)$ & $5.08(4.81 ; 5.34)$ & 0.000 \\
\hline Insulin* (mIU/l) & $\begin{array}{c}10.57 \\
(7.91 ; 14.08)\end{array}$ & $\begin{array}{c}9.78 \\
(7.25 ; 13.70)\end{array}$ & 0.010 & $9.80(7.6 ; 12.17)$ & $8.4(6.42 ; 11.61)$ & 0.001 & $11.84(9.24 ; 15.16)$ & $\begin{array}{c}11.30 \\
(8.85 ; 15.29)\end{array}$ & 0.626 & $13.93(9.72 ; 19.84)$ & $\begin{array}{c}15.98 \\
(11.22 ; 24.83)\end{array}$ & 0.001 \\
\hline $\begin{array}{l}\text { C-peptide* } \\
\text { (nmol/l) }\end{array}$ & $0.75(0.63 ; 0.89)$ & $0.69(0.57 ; 0.86)$ & 0.000 & $0.71(0.60 ; 0.82)$ & $0.64(0.53 ; 0.77)$ & 0.000 & $0.79(0.68 ; 0.91)$ & $0.78(0.65 ; 0.92)$ & 0.723 & $0.92(0.74 ; 1.13)$ & $0.94(0.77 ; 1.23)$ & 0.040 \\
\hline HOMA-IR* & $2.26(1.66 ; 3.11)$ & $2.23(1.63 ; 3.20)$ & 0.681 & $2.09(1.54 ; 2.72)$ & $1.89(1.43 ; 2.71)$ & 0.099 & $2.52(1.92 ; 3.32)$ & $2.65(1.91 ; 3.65)$ & 0.360 & $2.95(2.10 ; 4.29)$ & $3.56(2.51 ; 5.74)$ & 0.000 \\
\hline $\begin{array}{l}\text { C-peptide/ } \\
\text { Insulin* }\end{array}$ & $\begin{array}{c}10.09 \\
(8.37 ; 11.93)\end{array}$ & $\begin{array}{c}9.96 \\
(8.48 ; 12.09)\end{array}$ & 0.543 & $10.39(9.15 ; 12.13)$ & $10.47(8.97 ; 12.41)$ & 0.728 & $9.50(8.16 ; 11.13)$ & $\begin{array}{c}9.52 \\
(7.99 ; 11.24)\end{array}$ & 0.814 & $9.21(7.73 ; 11.15)$ & $\begin{array}{c}8.54 \\
(6.98 ; 10.08)\end{array}$ & 0.000 \\
\hline $\mathrm{TG}^{*}(\mathrm{mmol} / \mathrm{l})$ & $0.87(0.67 ; 1.18)$ & $0.82(0.63 ; 1.08)$ & 0.002 & $0.83(0.65 ; 1.19)$ & $0.74(0.58 ; 0.92)$ & 0.000 & $0.90(0.66 ; 1.18)$ & $0.94(0.66 ; 1.23)$ & 0.714 & $0.96(0.74 ; 1.38)$ & $1.12(0.82 ; 1.64)$ & 0.000 \\
\hline $\mathrm{GMT}^{*}(\mu \mathrm{kat} / \mathrm{l})$ & $0.20(0.17 ; 0.25)$ & $\begin{array}{c}0.26 \\
(0.22 ; 0.337)\end{array}$ & 0.000 & $0.19(0.16 ; 0.24)$ & $0.25(0.21 ; 0.30)$ & 0.000 & $0.22(0.18 ; 0.30)$ & $0.30(0.25 ; 0.42)$ & 0.000 & $0.25(0.2 ; 0.32)$ & $0.34(0.27 ; 0.51)$ & 0.000 \\
\hline fT3/fT4* & $0.35(0.32 ; 0.40)$ & $0.39(0.35 ; 0.44)$ & 0.000 & $0.35(0.32 ; 0.40)$ & $0.39(0.35 ; 0.44)$ & 0.000 & $0.36(0.32 ; 0.39)$ & $0.40(0.36 ; 0.46)$ & 0.000 & $0.35(0.31 ; 0.40)$ & $0.40(0.36 ; 0.46)$ & 0.000 \\
\hline $\mathrm{SHBG}^{*}(\mathrm{nmol} / \mathrm{l})$ & $\begin{array}{c}57.77 \\
(37.35 ; 82.62)\end{array}$ & $\begin{array}{c}31.63 \\
(23.15 ; 43.80)\end{array}$ & 0.000 & $\begin{array}{c}63.04 \\
(45.26 ; 89.82)\end{array}$ & $\begin{array}{c}35.45 \\
(25.94 ; 48.58)\end{array}$ & 0.000 & $44.50(27.99 ; 71.62)$ & $\begin{array}{c}29.49 \\
(21.76 ; 43.38)\end{array}$ & 0.000 & $31.90(22.59 ; 45.54)$ & $\begin{array}{c}22.62 \\
(15.76 ; 43.78)\end{array}$ & 0.000 \\
\hline $\begin{array}{l}\text { Testosterone* } \\
(\mathrm{nmol} / \mathrm{l})\end{array}$ & $0.30(0.22 ; 0.40)$ & $5.25(4.02 ; 6.73)$ & 0.000 & $0.30(0.22 ; 0.41)$ & $5.97(4.72 ; 7.10)$ & 0.000 & $0.31(0.23 ; 0.43)$ & $4.60(3.32 ; 6.41)$ & 0.000 & $0.36(0.26 ; 0.48)$ & $2.96(1.75 ; 4.34)$ & 0.000 \\
\hline $\begin{array}{l}\text { Adiponectin* } \\
\text { (mg/l) }\end{array}$ & $\begin{array}{c}7.82 \\
(5.36 ; 10.56)\end{array}$ & $6.00(4.55 ; 8.17)$ & 0.000 & $8.61(6.09 ; 11.04)$ & $6.59(5.05 ; 8.43)$ & 0.000 & $6.34(4.86 ; 8.98)$ & $5.28(4.00 ; 7.42)$ & 0.001 & $5.58(3.96 ; 7.81)$ & $4.52(3.30 ; 6.00)$ & 0.000 \\
\hline $\begin{array}{l}\text { Ghrelin* } \\
\text { (pg/ml) }\end{array}$ & $\begin{array}{c}669.11 \\
(503.72 ; 899.49)\end{array}$ & $\begin{array}{c}600.59 \\
(459.78 ; 829.32)\end{array}$ & 0.000 & $\begin{array}{c}688.97 \\
(507.15 ; 918.92)\end{array}$ & $\begin{array}{c}597.65 \\
(460.22 ; 869.06)\end{array}$ & 0.006 & $\begin{array}{c}646.55 \\
(520.87 ; 862.62)\end{array}$ & $\begin{array}{c}580.91 \\
(480.43 ; 783.88)\end{array}$ & 0.138 & $\begin{array}{c}582.61 \\
(445.71 ; 759.52)\end{array}$ & $\begin{array}{c}543.17 \\
(406.74 ; 686.29)\end{array}$ & 0.012 \\
\hline Leptin* (ng/ml) & $4.81(3.07 ; 7.29)$ & $0.89(0.51 ; 2.18)$ & 0.000 & $4.02(2.81 ; 5.81)$ & $0.63(0.41 ; 0.89)$ & 0.000 & $7.25(5.27 ; 9.96)$ & $2.16(1.21 ; 3.20)$ & 0.000 & $9.41(6.20 ; 14.69)$ & $5.48(3.28 ; 8.32)$ & 0.000 \\
\hline PAl-1* (ng/ml) & $2.97(2.04 ; 3.94)$ & $3.03(2.35 ; 4.10)$ & 0.002 & $2.64(1.89 ; 3.43)$ & $2.79(2.21 ; 3.57)$ & 0.033 & $3.46(2.45 ; 4.70)$ & $3.37(2.74 ; 4.45)$ & 0.842 & $4.40(3.19 ; 6.19)$ & $4.87(3.53 ; 6.76)$ & 0.013 \\
\hline $\begin{array}{l}\text { HOMA-IR > } 2.5 \\
(n, \%)\end{array}$ & $314(40.50 \%)$ & 304 (40.90\%) & $0.874^{+}$ & $98(30.40 \%)$ & $82(28.00 \%)$ & $0.505^{\dagger}$ & $58(50.00 \%)$ & 59 (51.80\%) & $0.790^{\dagger}$ & 251 (65.90\%) & $228(75.50 \%)$ & $0.006^{+}$ \\
\hline $\begin{array}{l}\text { HOMA-IR > } 4 \\
(n, \%)\end{array}$ & 84 (10.80\%) & 106 (14.30\%) & $0.044^{+}$ & 15 (4.70\%) & $21(7.20 \%)$ & $0.186^{\dagger}$ & $13(11.20 \%)$ & $20(17.50 \%)$ & $0.170^{+}$ & $111(29.10 \%)$ & $133(44.00 \%)$ & $0.000^{+}$ \\
\hline IFG (n,\%) & $34(4.40 \%)$ & 72 (9.70\%) & $0.000^{+}$ & $12(3.70 \%)$ & $20(6.80 \%)$ & $0.084^{\dagger}$ & $2(1.70 \%)$ & 15 (13.20\%) & $0.001^{\dagger}$ & $22(5.80 \%)$ & 29 (9.60\%) & $0.060^{\dagger}$ \\
\hline T2DM (n,\%) & $1(0.13 \%)$ & $2(0.27)$ & $\neq$ & 0 & 0 & -- & 0 & 0 & --- & $2(0.50 \%)$ & $1(0.30 \%)$ & $\neq$ \\
\hline
\end{tabular}

BMI, body mass index; T2DM, type 2 diabetes; FBG, fasting blood glucose; fT3/fT4, ratio of free triiodothyronine to free thyroxine; GMT, gamma-glutamyltransferase; HOMA-IR, homeostasis model assessment of insulin resistance; IFG, impaired fasting glucose; PAl-1, plasminogen activator inhibitor-1; TG, triglycerides. * Data are described as median, lower and upper quartiles. ${ }^{\dagger}$ Chi-test was used. ${ }^{\ddagger}$ Not calculated due to small number of probands. Data significant at $\mathrm{p}<0.05$. 
Table 2 HOMA-IR values in relation to the number of metabolic syndrome components

\begin{tabular}{|c|c|c|}
\hline \multirow{2}{*}{$\begin{array}{l}\text { Number of metabolic } \\
\text { syndrome components } \\
\text { (number of girls/boys) }\end{array}$} & \multicolumn{2}{|l|}{ HOMA-IR } \\
\hline & Girls & Boys \\
\hline 0 (468/301 girls/boys) & $2.12(1.53 ; 2.84)$ & $1.90(1.42 ; 2.61)$ \\
\hline 1 ( $381 / 359$ girls/boys) & $2.55(1.80 ; 3.45)$ & $2.28(1.65 ; 3.11)$ \\
\hline 2 (174/168 girls/boys) & $2.85(2.09 ; 4.37)$ & $3.19(2.20 ; 5.03)$ \\
\hline 3 (54/76 girls/boys) & $3.60(2.56 ; 5.69)$ & $4.44(2.88 ; 6.25)$ \\
\hline 4 (4/29 girls/boys) & $5.86(4.90 ; 9.19)$ & $6.38(4.26 ; 7.98)$ \\
\hline 5 (0/3 girls/boys) & --- & $7.19(4.33 ; 13.93)$ \\
\hline
\end{tabular}

HOMA-IR, homeostasis model assessment of insulin resistance. Data are described as median, lower and upper quartiles.

same predictors but the HOMA-IR variability was explained by $28.9 \%$ (Figures 1 and 2). Construction of the second predictive model was based on inclusion of the minimum of widely used parameters in clinical practice such as age, BMI, ratio of fT3 to fT4, GMT activity, levels of TG and SHBG. The model showed still satisfactory predictability (37.8\% variability of the dependent variable explained by OPLS method in boys, resp. $20.5 \%$ in girls).

\section{Discussion}

\section{Disturbances of glucose metabolism and IR}

Our study of Czech adolescents presents an overview of glucose metabolism with respect to different weight categories and to gender. To date, there are no data on glucose homeostasis disturbances in Czech adolescents. In the representative cohort of Czech adolescents, IFG was found in $7.0 \%$ with a higher prevalence in boys than in girls (9.7 vs. 4.4\%). This finding is in accordance with US data which showed similar overall prevalence of IFG in adolescents and also higher prevalence in boys than in girls (10.0\% vs. $4.0 \%)$ [14]. We further showed that boys are at greater risk for IFG regardless weight status. Our results of an overall prevalence of type 2 diabetes in general population $(0.2 \%)$ and obese adolescents $(0.4 \%)$ indicate that type 2 diabetes is still a rare diagnosis even in the population of obese Czech adolescents. It is known that the prevalence varies by ethnicity and that much greater prevalence of type 2 diabetes is found in the US non-White European descent [15]. Lower prevalence of type 2 diabetes may partly be explained by ethnically homogenous Czech Caucasian population. In contrast to results from US it has been demonstrated that type 2 diabetes in the Northern and Central Europe is still rarely diagnosed even in obese children [16]. It is highly interesting that the level of fasting blood glucose was similar across weight categories but always significantly higher in boys than in girls. Brandou et al. found that the level of blood glucose was significantly higher in obese than in normal weight children but only in prepubertal period [31]. Several studies concluded that men had tendency towards higher prevalence of abnormalities of glucose homeostasis than women [32,33]. A recent study performed on Chinese

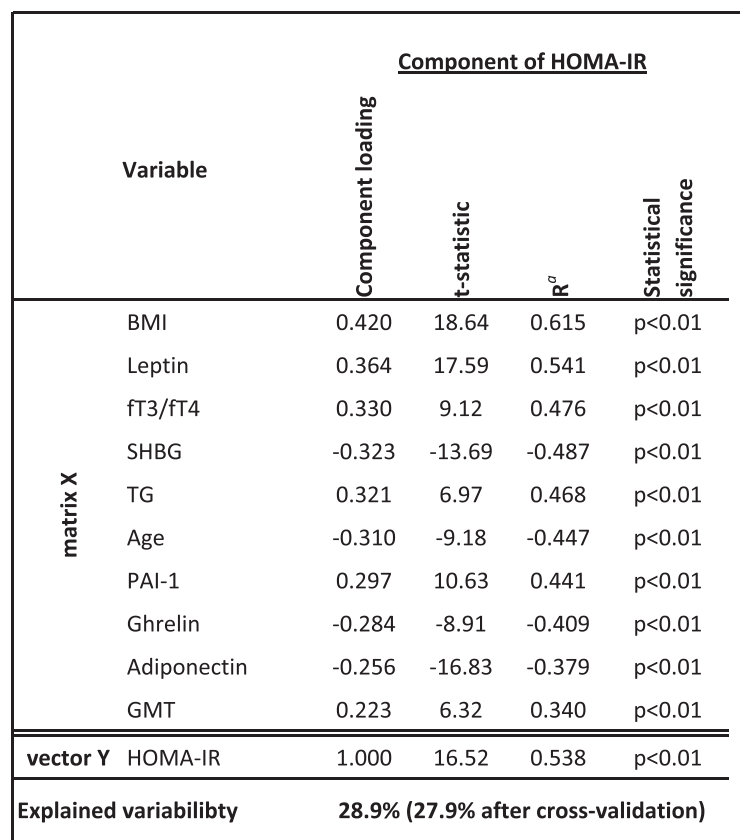

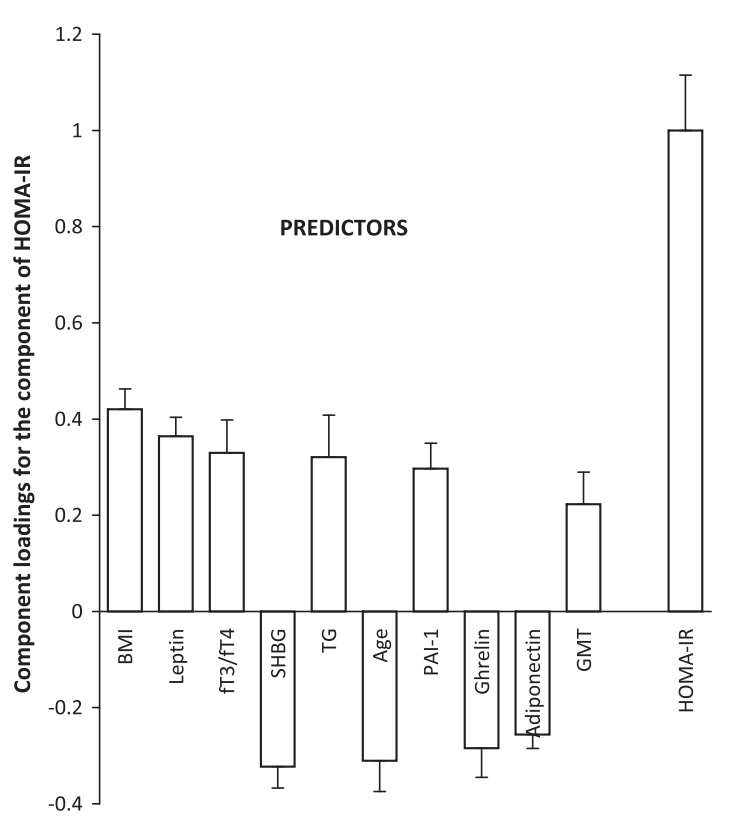

Figure 1 Relationships between HOMA-IR (vector $\mathbf{Y}$ ) and major predictors (matrix $\mathbf{X}$ ) for girls. Ra is a component loading expressed as a correlation coefficient with the predictive component. T-statistic is a ratio of component loading and statistical error. BMI, body mass index; fT3/fT4, ratio of free triiodothyronine to free thyroxine; GMT, gamma-glutamyl aminotransferase; HOMA-IR, homeostasis model assessment of insulin resistance; PAI-1, plasminogen activator inhibitor-1; SHBG, sex hormone-binding globulin; TG, triglycerides. 


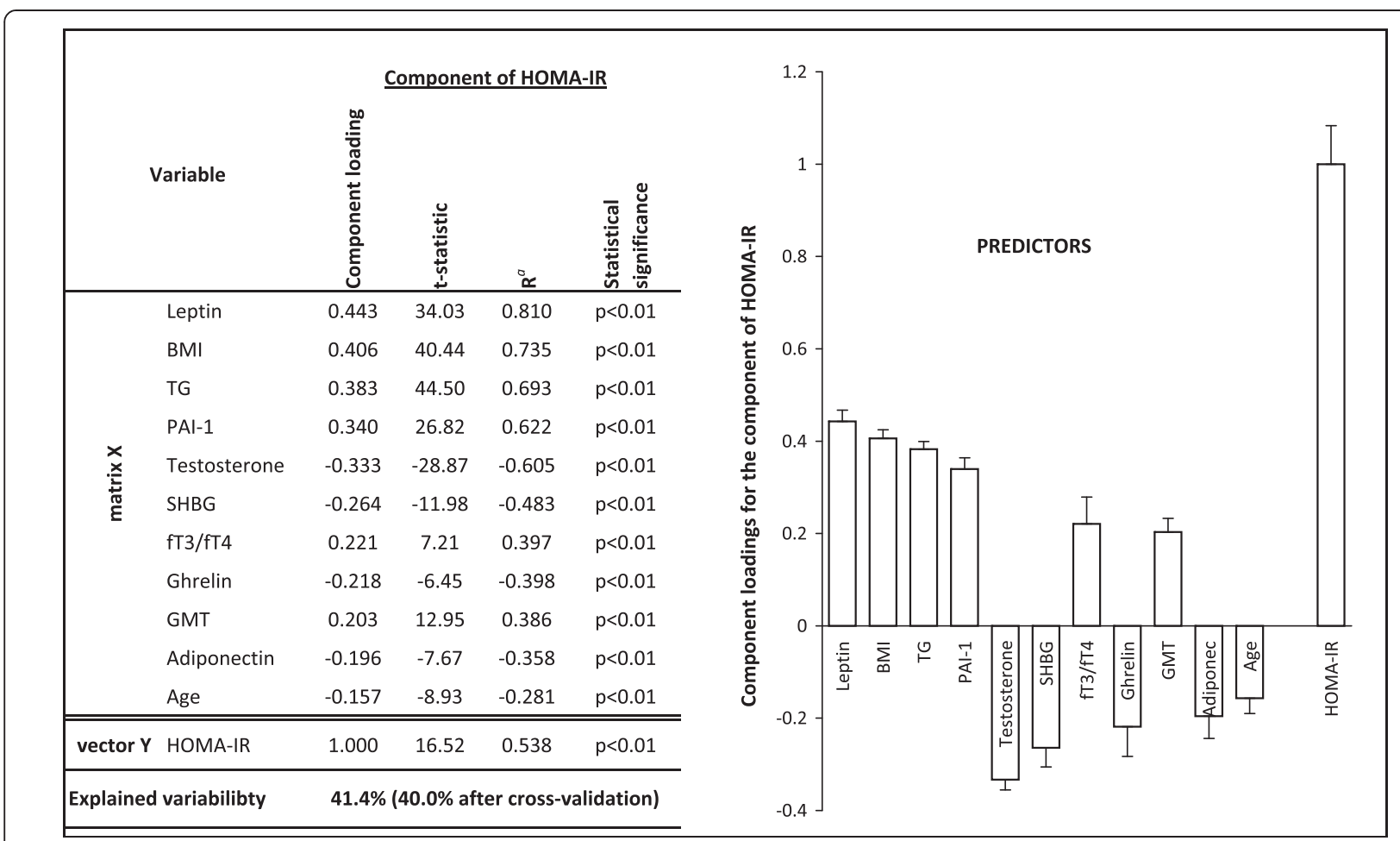

Figure 2 Relationships between HOMA-IR (vector Y) and major predictors (matrix X) for boys. Ra is a component loading expressed as a correlation coefficient with the predictive component. T-statistic is a ratio of component loading and statistical error. BMl, body mass index; fT3/fT4, ratio of free triiodothyronine to free thyroxine; GMT, gamma-glutamyl aminotransferase; HOMA-IR, homeostasis model assessment of insulin resistance; PAI-1, plasminogen activator inhibitor-1; SHBG, sex hormone-binding globulin; TG, triglycerides.

children and adolescents has also reported significantly higher levels of fasting blood glucose in boys in comparison to girls regardless of weight status [20]. Our results as conclusions of others indicate that the HOMA-IR cutoff point of 2.5 is not suitable for adolescence [9]. Interestingly, only in the obese group there was a significant gender difference in the prevalence of IR. This result emphasizes the fact that obese adolescent boys are at greater risk for IR than girls of comparable degree of obesity.

It has already been demonstrated by several investigators that gender has an effect on insulin sensitivity $[1,3,4,9,34]$. In normal weight Czech adolescents as well as in the general population cohort, levels of insulin and Cpeptide were found significantly higher in girls than in boys. This finding would therefore confirm the fact than at puberty girls tend to be more insulin resistant than boys. Several studies showed a higher IR in girls than in boys even after adjustment for weight status, several anthropometric parameters, race and ethnicity $[1,4]$. According to our results, obesity in males led to a significantly higher levels of insulin, C-peptide, HOMA-IR and lower $\mathrm{C}$-peptide to insulin ratio than in obese girls. This is in line with conclusion of Kurtoglu et al. who demonstrated that HOMA-IR cut-off values in the pubertal stage were significantly higher in boys than in girls [10].
HOMA-IR thresholds associated with cardiometabolic risks HOMA-IR was shown to be a useful tool to detect children and adolescents with metabolic syndrome [8]. As expected and in accordance with the study of Chinese children and teenagers we confirmed the trend of increasing HOMA-IR values with the increasing number of metabolic syndrome components [35]. At adolescence, HOMA-IR thresholds of 3.6 for girls and 4.4 for boys were associated with increased cardiometabolic risks. In the agreement with the conclusion of Kurtoglu et al., we also emphasize the necessity of gender specific cut-off thresholds [10].

\section{HOMA-IR prediction}

According to our findings, a broad variety of parameters had a predictive power for HOMA-IR. As expected the majority of studied anthropometric parameters played a role in the index prediction. Due to the fact that the prediction rate among anthropometric parameters was similar, only BMI was included for further model assessment. $\mathrm{BMI}$ is widely used in clinical practice, in epidemiological studies and according to our findings had a comparable prediction to other anthropometric parameters, e.g. waist circumference. A study by Bosy-Westphal et al. concluded that waist circumference and BMI have an equivalent 
value for obesity-related metabolic risk assessment [36]. The same study also showed that measurement of body fat mass has no advantage over BMI and waist circumference in the prediction of obesity-related metabolic risk [36]. We are aware of the fact that in normal weight but insulin resistant subjects other factors than BMI probably play a role in the development of IR, e.g. fat distribution, family history. According to our predictive models, age in girls seemed to be stronger predictor of HOMA-IR than in boys. Younger age particularly in girls was associated with higher HOMA-IR. This is probably due to the fact that younger girls of our cohort were at the peak of IR associated with puberty.

In our cohort, GMT activity and levels of TG, SHBG, leptin, PAI-1, ghrelin and adiponectin in both genders and testosterone in boys were revealed as key components in HOMA-IR prediction. A strong correlation between IR and TG has already been confirmed by several studies [37]. Significant associations between IR and non-alcoholic fatty liver disease as well as similar risk and protective factors for these two inter-related disorders are known $[38,39]$. It is well recognized that GMT activity is a marker of oxidative stress and is associated with an increased risk of cardiovascular disease and components of metabolic syndrome [40].

According to our results, testosterone was associated with HOMA-IR prediction in boys. Testosterone is usually decreased in obese males than in their lean counterparts. It has also been shown that glucose disposal was significantly associated with serum testosterone, even after controlling for BMI and Tanner stage and thus, linking the presence of IR with hypogonadism [41]. The level of SHBG was found as an important predictor of IR in both genders. A strong correlation between level of leptin and IR measured by HOMA-IR even after adjustment for gender and BMI has previously been shown [42]. In a recently published study, leptin was also found as a strong and independent predictor of HOMA-IR in boys and in girls [20]. However, some authors indicated this relationship due to increased fat mass [43]. PAI-1 represents an independent risk factor for cardiovascular diseases and its level and activity is increased in type 2 diabetics [44]. A study on young adults demonstrated that PAI-1 concentrations were higher in subjects with impaired glucose tolerance than in subjects with normal glucose tolerance even having comparable age, BMI, waist circumference and fat mass [44]. In relation to HOMA-IR, ghrelin was another parameter with a predictive power in Czech girls and boys. Bacha et al. suggested that ghrelin suppression might be another feature of IR in overweight adolescents [23]. A correlation of adiponectin with IR has already been demonstrated [21,22].

In the analyses, in which all studied parameters had been taken into account, TSH in both genders, fT4 in boys and fT3 in girls were found to have some predictive power for HOMA-IR. However, the ratio of fT3 to fT4 had stronger prediction than the above mentioned parameters, thus we included this ratio in the predictive models. Several studies demonstrated that a higher fT3 to fT4 ratio is associated with various markers of unfavorable metabolic profile and cardiovascular risk [45].

The existence of such a difference in prediction variability between boys and girls is rather interesting. Boys presented with higher prediction in all models regardless number of components. We assume that this might be due to the major influence of increased insulin level in girls as the consequence of pubertal physiological IR.

The major limitation of our study is the lack of data on the presence of acanthosis nigricans as the clinical sign of IR and the lack of the assessment of pubertal status in our adolescents. According to a unique longitudinal study performed in our country in years 19611982 , the average age of pubertal maturity was $15.5-16.0$ years in boys and 13.0 years in girls [46]. We thus assume that probably all of the girls and the majority of boys of our cohort have entered puberty at the time of investigation.

\section{Conclusions}

In conclusion, type 2 diabetes in Czech adolescents even in obese individuals was rarely diagnosed. Findings of significantly higher level of blood glucose and higher prevalence of IFG regardless of weight status in boys than in girls lead us to a conclusion that adolescent boys in general are at greater risk of glucose disturbances in comparison to adolescent girls. This is further supported by our results that showed obese boys more insulin resistant than obese girls. In adolescence, HOMA-IR of 3.6 for girls and of 4.4 for boys were identified as cut-off values that corresponded to increased cardiometabolic risks. Several parameters seemed to play a role in HOMA-IR prediction. Major predictors for both genders were age, BMI, ratio of fT3 to fT4, GMT activity and levels of TG and SHBG.

\section{Abbreviations \\ BMI: Body mass index; FBG: Fasting blood glucose; fT3: Free triiodothyronine; fT4: Free thyroxine; GMT: Gamma-glutamyltransferase; HOMA-IR: Homeostasis model assessment of insulin resistance; IFG: Impaired fasting glucose; IR: Insulin resistance; OPLS: Orthogonal projections to latent structures; PAI-1: Plasminogen activator inhibitor-1; SHBG: Sex hormone-binding globulin; TG: Triglyceride; T2DM: Type 2 diabetes; US: United States.}

\section{Competing interests}

The authors declare that they have no competing interests.

\section{Authors' contributions}

$\mathrm{IAH}$ and $\mathrm{HZ}$ researched data and designed the study. IAH wrote the manuscript. $\mathrm{HZ}$ and $\mathrm{MH}$ performed statistical analyses and prepared all the tables and figures. VH and MK reviewed the manuscript and contributed to discussion. LD, BS and $\mathrm{RH}$ performed all laboratory investigations. $\mathrm{PH}$ was responsible for clinical examination of the studied individuals. All authors read and approved the final manuscript. 


\section{Acknowledgements}

This study was supported by grants: NT/13792-4 Internal Grant Agency of the Ministry of Health of the Czech Republic (funding of study design and manuscript submission, funding of LD, BS, MH, MK and VH), NT/12342-5/2011 Internal Grant Agency of the Ministry of Health of the Czech Republic (funding of biochemical analyses, funding of PH), CZ0123 from Norway through the Norwegian Financial Mechanisms (funding of cohort collection, clinical examination, biochemical analyses, funding of RH) and PRVOUK P31 (funding of statistical analyses and data interpretation, funding of IAH and HZ). We would like to thank the study participants and their families, participating pediatricians and weight management centers.

\section{Author details}

${ }^{1}$ Institute of Endocrinology, Obesity Management Center, Národní 8, 11694 Prague 1, Czech Republic. ${ }^{2}$ Department of Pediatrics and Center for Research of Diabetes, Metabolism and Nutrition, Third Faculty of Medicine, Charles University, Šrobárova 50, 10034 Praque 10, Czech Republic. ${ }^{3}$ Faculty of Science, Charles University, Albertov 6, 12843 Prague 2, Czech Republic.

Received: 8 June 2014 Accepted: 16 August 2014

Published: 16 September 2014

\section{References}

1. Lee JM, Okumura MJ, Davis MM, Herman WH, Gurney JG: Prevalence and determinants of insulin resistance among U.S. adolescents: a population-based study. Diabetes Care 2006, 29:2427-2432.

2. Caprio S, Cline G, Boulware S, Permnente C, Shulman Gl, Sherwin RS, Tamborlane WV: Effects of puberty and diabetes on metabolism of insulin-sensitive fuels. Am J Physiol 1994, 266:E885-E891.

3. Travers SH, Jeffers BW, Bloch CA, Hill JO, Eckel RH: Gender and Tanner stage differences in body composition and insulin sensitivity in early pubertal children. J Clin Endocrinol Metab 1995, 80:172-178.

4. Moran A, Jacobs DR Jr, Steinberger J, Hong C-P, Prineas R, Luepker RV Sinaiko AR: Insulin resistance during puberty: results from clamp studies in 357 children. Diabetes 1999, 48:2039-2044.

5. Matthews DR, Hosker JP, Rudenski AS, Naylor BA, Treacher DF, Turner RC: Homeostasis model assessment: insulin resistance and beta-cell function from fasting plasma glucose and insulin concentrations in man. Diabetologia 1985, 28:412-419.

6. Conwell LS, Trost SG, Brown WJ, Batch JA: Indexes of insulin resistance and secretion in obese children and adolescents: a validation study. Diabetes Care 2004, 27:314-319.

7. Haymond MW: Measuring insulin resistance: a task worth doing: but how? Pediatr Diabetes 2003, 4:115-118.

8. Tresaco B, Bueno G, Pineda I, Moreno LA, Garagorri JM, Bueno M: Homeostatic model assessment (HOMA) index cut off values to identify the metabolic syndrome in children. J Physiol Biochem 2005, 61:381-388.

9. Keskin M, Kurtoglu S, Kendirci M, Atabek ME, Yazici C: Homeostasis model assessment is more reliable than the fasting glucose/insulin ratio and quantitative insulin sensitivity check index for assessing insulin resistance among obese children and adolescents. Pediatrics 2005, 115:e500-e503.

10. Kurtoğlu S, Hatipoğlu N, Mazıcıoğlu M, Kendirici M, Keskin M, Kondolot M: Insulin resistance in obese children and adolescents: HOMA-IR cut-off levels in the prepubertal and pubertal periods. J Clin Res Pediatr Endocrinol 2010, 2:100-106.

11. Rodden AM, Diaz VA, Mainous AG 3rd, Koopman RJ, Geesey ME: Insulin resistance in adolescents. J Pediatr 2007, 151:275-279.

12. Jiang $X$, Srinivasan $S R$, Radhakrishnamurthy B, Dalferes ER, Berenson GS: Racial (black-white) differences in insulin secretion and clearance in adolescents: The Bogalusa Heart Study. Pediatrics 1996, 97:357-360.

13. American Diabetes Association: Standards of medical care in diabetes-2010. Diabetes Care 2010, 33(Suppl 1):S11-S61.

14. Williams DE, Cadwell BL, Cheng YJ, Cowie CC, Gregg EW, Geiss LS, Engelgau MM, Narayan KM, Imperatore G: Prevalence of impaired fasting glucose and its relationship with cardiovascular disease risk factors in US adolescents, 1999-2000. Pediatrics 2005, 116:1122-1126.

15. Writing Group for the SEARCH for Diabetes in Youth Study Group, Dabelea D, Bell RA, D'Agostino RB Jr, Imperatore G, Johansen JM, Linder B, Liu LL, Loots B, Marcovina S, Mayer-Davis EJ, Pettitt DJ, Waitzfelder B:
Incidence of diabetes in youth in the United States. JAMA 2007, 97:2716-2724.

16. Wiegand S, Maikowski U, Blankenstein O, Biebermann H, Tarnow P, Grüters A: Type 2 diabetes and impaired glucose tolerance in European children and adolescents with obesity - a problem that is no longer restricted to minority groups. Eur J Endocrinol 2004, 151:199-206.

17. Mazur A, Grzywa M, Małecka-Tendera E, Telega G: Prevalence of glucose intolerance in school age children. Population based cross-sectional study. Acta Paediatr 2007, 96:1799-1802.

18. Malecka-Tendera E, Erhardt E, Molnár D: Type 2 diabetes mellitus in European children and adolescents. Acta Paediatr 2005, 94:543-546.

19. Lee S, Bacha F, Gungor N, Arslanian SA: Waist circumference is an independent predictor of insulin resistance in black and white youths. J Pediatr 2006, 148:188-194.

20. Xu L, Li M, Yin J, Cheng H, Yu M, Zhao X, Xiao X, Mi J: Change of body composition and adipokines and their relationship with insulin resistance across pubertal development in obese and nonobese Chinese children: the BCAMS study. Int J Endocrinol 2012, 2012:389108.

21. Bush NC, Darnell BE, Oster RA, Goran Ml, Gower BA: Adiponectin is lower among African Americans and is independently related to insulin sensitivity in children and adolescents. Diabetes 2005, 54:2772-2778.

22. Lee S, Bacha F, Gungor N, Arslanian SA: Racial differences in adiponectin in youth: relationship to visceral fat and insulin sensitivity. Diabetes Care 2006, 29:51-56.

23. Bacha F, Arslanian SA: Ghrelin suppression in overweight children: a manifestation of insulin resistance? J Clin Endocrinol Metab 2005, 90:2725-2730

24. Lambadiari V, Mitrou P, Maratou E, Raptis AE, Tountas N, Raptis SA, Dimitriadis $\mathrm{G}$ : Thyroid hormones are positively associated with insulin resistance early in the development of type 2 diabetes. Endocrine 2011, 39:28-32.

25. Kobzova J, Vignerova J, Blaha P, Krejcovsky L, Riedlova J: The 6th nationwide anthropological survey of children and adolescents in the Czech Republic in 2001. Cent Eur J Public Health 2004, 12:126-130.

26. Aldhoon-Hainerová I, Zamrazilová H, Atkinson RL, Dušátková L, Sedláčková $B$, Hlavatý P, Lee ZP, Kunešová M, Hainer V: Clinical and laboratory characteristics of 1179 Czech adolescents evaluated for antibodies to human adenovirus 36. Int J Obes (Lond) 2014, 38:285-291.

27. Haffner SM, Kennedy E, Gonzalez C, Stern MP, Miettinen H: A prospective analysis of the HOMA model. The Mexico City Diabetes Study. Diabetes Care 1996, 19:1138-1141.

28. Isomaa B, Almgren P, Tuomi T, Forsén B, Lahti K, Nissén M, Taskinen MR, Groop L: Cardiovascular morbidity and mortality associated with the metabolic syndrome. Diabetes Care 2001, 24:683-689.

29. Alberti KG, Zimmet P, Shaw J, IDF Epidemiology Task Force Consensus Group: The metabolic syndrome-a new worldwide definition. Lancet 2005, 366:1059-1062.

30. Hill M, Parízek A, Kancheva R, Dusková M, Velíková M, Kríz L, Klímková M, Pasková A, Zizka Z, Matucha P, Meloun M, Stárka L: Steroid metabolome in plasma from the umbilical artery, umbilical vein, maternal cubital vein and in amniotic fluid in normal and preterm labor. I Steroid Biochem Mol Biol 2010, 21:594-610.

31. Brandou F, Brun JF, Mercier J: Limited accuracy of surrogates of insulin resistance during puberty in obese and lean children at risk for altered glucoregulation. J Clin Endocrinol Metab 2005, 90:761-767.

32. Kuhl J, Hilding A, Ostenson CG, Grill V, Efendic S, Bavenholm P. Characterisation of subjects with early abnormalities of glucose tolerance in the Stockholm Diabetes Prevention Programme: the impact of sex and type 2 diabetes heredity. Diabetologia 2005, 48:35-40.

33. DECODE Study Group: Age- and sex-specific prevalences of diabetes and impaired glucose regulation in 13 European cohorts. Diabetes Care 2003, 26:61-69.

34. Brufani C, Tozzi A, Fintini D, Ciampalini P, Grossi A, Fiori R, Kiepe D, Manco M, Schiaffini R, Porzio O, Cappa M, Barbetti F: Sexual dimorphism of body composition and insulin sensitivity across pubertal development in obese Caucasian subjects. Eur J Endocrinol 2009, 160:769-775.

35. Yin J, Li M, Xu L, Wang Y, Cheng H, Zhao X, Mi J: Insulin resistance determined by Homeostasis Model Assessment (HOMA) and associations with metabolic syndrome among Chinese children and teenagers. Diabetol Metab Syndr 2013, 15:71. 
36. Bosy-Westphal A, Geisler C, Onur S, Korth O, Selberg O, Schrezenmeir J, Müller MJ: Value of body fat mass vs anthropometric obesity indices in the assessment of metabolic risk factors. Int J Obes (Lond) 2006, 30:475-483.

37. Bao W, Srinivasan SR, Berenson G: Persistent elevation of plasma insulin levels is associated with increased cardiovascular risk in children and young adults. The Bogalusa Heart Study. Circulation 1996, 93:54-59.

38. Kelishadi R, Cook SR, Amra B, Adibi A: Factors associated with insulin resistance and non-alcoholic fatty liver disease among youths. Atherosclerosis 2009, 204:538-543.

39. Denzer C, Thiere D, Muche R, Koenig W, Mayer H, Kratzer W, Wabitsch M: Gender-specific prevalences of fatty liver in obese children and adolescents: roles of body fat distribution, sex steroids, and insulin resistance. J Clin Endocrinol Metab 2009, 94:3872-3881.

40. Mason JE, Starke RD, Van Kirk JE: Gamma-glutamyl transferase: a novel cardiovascular risk biomarker. Prev Cardiol 2010, 13:36-41.

41. Moriarty-Kelsey M, Harwood JE, Travers SH, Zeitler PS, Nadeau KJ: Testosterone, obesity and insulin resistance in young males: evidence for an association between gonadal dysfunction and insulin resistance during puberty. J Pediatr Endocrinol Metab 2010, 23:1281-1287.

42. Silha JV, Krsek M, Skrha JV, Sucharda P, Nyomba BL, Murphy LJ: Plasma resistin, adiponectin and leptin levels in lean and obese subjects: correlations with insulin resistance. Eur J Endocrinol 2003, 149:331-335.

43. Cnop M, Landchild MJ, Vidal J, Havel PJ, Knowles NG, Carr DR, Wang F, Hull RL, Boyko EJ, Retzlaff BM, Walden CE, Knopp RH, Kahn SE: The concurrent accumulation of intra-abdominal and subcutaneous fat explains the association between insulin resistance and plasma leptin concentrations: distinct metabolic effects of two fat compartments. Diabetes 2002, 51:1005-1015.

44. Pannacciulli N, De Mitrio V, Marino R, Giorgino R, De Pergola G: Effect of glucose tolerance status on PAl-1 plasma levels in overweight and obese subjects. Obes Res 2002, 10:717-725.

45. Roef GL, Rietzschel ER, Van Daele CM, Taes YE, De Buyzere ML, Gillebert TC, Kaufman JM: Triiodothyronine and free thyroxine levels are differentially associated with metabolic profile and adiposity-related cardiovascular risk markers in euthyroid middle-aged subjects. Thyroid 2014, 24:223-231.

46. Bouchalová M: Development during childhood and its influences: Brno growth study. Prague: Avicenum; 1987.

doi:10.1186/1758-5996-6-100

Cite this article as: Aldhoon-Hainerová et al:: Glucose homeostasis and insulin resistance: prevalence, gender differences and predictors in adolescents. Diabetology \& Metabolic Syndrome 2014 6:100.

\section{Submit your next manuscript to BioMed Central and take full advantage of:}

- Convenient online submission

- Thorough peer review

- No space constraints or color figure charges

- Immediate publication on acceptance

- Inclusion in PubMed, CAS, Scopus and Google Scholar

- Research which is freely available for redistribution 